\title{
Knowledge about the Right to Information Act of Sri Lanka among the Trainees of Postgraduate Institute of Medicine of Sri Lanka
}

\author{
I.R.H.S. Ihalagama ${ }^{1}{ }^{*}$, C.A.D.M.N.C. Kolambage ${ }^{1}$, P.V.A.I. Gunawardena ${ }^{1}$, \\ S.D. Siriwardane ${ }^{1}$ \\ 1 Post Graduate Institute of Medicine, University of Colombo, Sri Lanka \\ *sathyajithihalagama@gmail.com \\ https://orcid.org/0000-0002-0285-4355
}

\begin{abstract}
Introduction: Right to Information Act (RTI) of Sri Lanka implemented in 2016, describes the rights and level of access to information in the public authorities in the country. In the healthcare sector, information plays a major role; persuading health care providers to be conscious of the contents of the Act. The purpose of this survey was to assess the level of knowledge and to get recommendations on methods to improve awareness on RTI act among the trainees of the Postgraduate Institute of Medicine (PGIM).
\end{abstract}

Methods: An electronic questionnaire was distributed among all the trainees currently attached to the PGIM. The questionnaire included 16 questions, covering the main components of the Act. Marks were allocated according to the level of knowledge and feedback was given at the end of the questionnaire.

Results: Out of 116 Participants (Response rate $-10.1 \%$ ) responded to the online questionnaire, the highest number of participants were from General Medical specialties (18\%). Other participants were from Biomedical Informatics (17\%), General Surgical specialties (16\%), Gynaecology and Obstetrics (7\%), Pathology (5\%) and Medical Administration (4\%) streams. The average point score was $47 \%$. The points ranged from $6 \%$ (only one answer is correct) to $94 \%$ (only one answer is wrong). The results of the survey show an inadequate knowledge, considering the direct questions based on the Act (Only 43\% correct answers). In contrast, scenario-based questions recorded higher scores (61\% correct answers). Furthermore, $96 \%$ of the participants believed that there should be an awareness program regarding RTI.

Conclusion: There is a knowledge gap pertaining to the contents of the RTI act among the PGIM trainees. This needs to be addressed with knowledge sharing sessions based on the needs of the trainees as it will be important in their career pathway.

Keywords: Right to Information Act, Post Graduate Trainees, Post Graduate Institute of Medicine, RTI Act, Survey on RTI Act 